\title{
Significance of the contacting and no contacting thermoelectric power measurements applied to grit blasted medical Ti6Al4V
}

\author{
H. Carreon ${ }^{1, *}$, S. Barriuso ${ }^{2}$, M. Lieblich ${ }^{2}$, J. L. González-Carrasco ${ }^{2,3}$, J.A. Jimenez ${ }^{2}$, \\ F. G. Caballero ${ }^{2}$ \\ ${ }^{1}$ Instituto de Investigaciones Metalúrgicas (UMSNH-IIM) \\ Ciudad Universitaria, Morelia, México \\ ${ }^{2}$ Centro Nacional de Investigaciones Metalúrgicas (CENIM-CSIC), \\ Avda Gregorio del Amo 8, E28040 Madrid, España. \\ ${ }^{3}$ Centro de Investigación Biomédica en Red en Bioingeniería, Biomateriales y \\ Nanomedicina (CIBER-BBN), Madrid, España
}

\begin{abstract}
Grit blasting is a surface plastic deformation technique aimed to increase the surface area available for bone/implant apposition, which contributes to improve fixation and mechanical stability of Ti6Al4V implants. Besides roughening, grit blasting also causes surface contamination with embedded grit particles and subtle subsurface microstructural changes that, although does not challenge their biocompatibility, might influence other surface dominated properties like corrosion and ion release. Additional benefits are expected due to the induced compressive residual stresses, hence enhancing fatigue strength. The net effect depends on the type of particles used for blasting, but also on the amount of the subsurface cold work associated to the severe surface plastic deformation. In this work we study the potential of the non-contacting and contacting thermoelectric power (TEP) measurements in the analysis of the global changes induced in the Ti6Al4V when blasting the alloy with $\mathrm{Al}_{2} \mathrm{O}_{3}$ or $\mathrm{ZrO}_{2}$ particles, which yields a coarse and a fine rough surface, respectively. To reveal the effect of residual stresses, a set of specimens were thermally treated. The study proves that the non-contacting technique is more sensitive to the presence of residual stresses, whereas the contact technique is strongly influenced by the grain size refinements, work hardening and changes in solute.
\end{abstract}

Keywords: Grit Blasting; Thermoelectric Measurements; Residual Stresses; Biomaterial; Titanium alloy

*Corresponding author: tel: + 011-52-443-316-7414. e-mail: hcarreon@umich.mx 


\section{INTRODUCTION}

316 LVM (low carbon vacuum melt) and Ti6Al4V alloys are the materials of choice for many structural implantable device applications and there is no reason to expect a change in the short and medium term. Despite their good corrosion resistance and reasonable biocompatibility, many efforts have been addressed to enhance their biofunctionality through surface modifications. Roughening of the implant by grit blasting is a low-cost solution to increase the surface area available for bone/implant apposition [1-3], which contributes to improve fixation and mechanical stability of implants. Typically examples for Ti-base alloys are dental implants or hip components. Severe surface plastic deformation by grit blasting is also considered an attractive modification of 316 LVM to improve fatigue strength of intramedullary nails for the proximal femur and diaphysary fractures, providing an optimal combination between high resistance during the consolidation period and a minimal invasive geometry. Additional benefits are expected due to the induced compressive residual stresses at the subsurface that could contribute to delay crack nucleation and further propagation, hence enhancing fatigue strength. The net effect depends on the roughness and in turn on the type of particles used for blasting, but also on the amount of the subsurface cold work associated to the severe surface plastic deformation [4]. Besides the primary residual stress effect, grit blasting also causes surface contamination with embedded grit particles and subtle subsurface microstructural changes that, although does not challenge their biocompatibility, might influence corrosion resistance and ion release [5,6]. Moreover, since maximum loads use to occur at the surface, they could play a detrimental role in the fatigue strength by acting as stress concentrators. Characterization of the global blasting induced effects becomes then of paramount importance for the intended medical applications. 
Residual stresses developed by blasting are usually evaluated by X-Ray diffraction (XRD) or synchrotron radiation X-ray diffraction (SR-XRD) $[7,8]$; whereas subsurface work hardening and the associated microstructural changes are assessed by combining scanning electron microscopy (SEM) and microhardness testing $[9,10]$. Thermoelectric power (TEP) measurements have recently been performed using the contacting and noncontacting techniques to detect the global blasting induced effects in the medical 316LVM stainless steel [11-13]. Development of small amounts of $\alpha^{\prime}$-martensite phase at the subsurface, however, was found to limit the applicability of the noncontacting thermoelectric technique. Elimination of the magnetic phase by appropriated thermal treatments after blasting revealed that both techniques offer complementary information useful for monitoring the global blasting induced effects.

In this work, we study the potential of the non-contacting and contacting thermoelectric power measurements in the analysis of the global changes induced by grit blasting on the Ti6Al4V alloy, where magnetic phases are not expected to form [4,7]. The attractiveness of this blasted alloy is primarily based on an excellent combination of corrosion resistance and biocompatibility, especially after thermal oxidation treatments [14-16].

\section{THERMOELECTRIC POWER TECHNIQUES}

Most existing thermoelectric techniques are based on the well-known Seebeck effect that is commonly used in thermo-couples to measure temperatures across junctions made of different materials. A variety of material properties can contribute to change the TEP of materials. The fact that metal sorting is a fundamental application of thermoelectric materials characterization stems from the fact that chemical composition exerts the strongest effect on the thermoelectric properties of the material [17]. 
However, it is known that under special conditions, different heat treatments, hardening, texture, fatigue, etc. can also produce an effective thermoelectric voltage between contacting materials of identical chemical composition $[18,19]$. Consequently, by using a reference electrode that is similar to the material being tested, we can reliably estimate small differences in TEP, thereby characterizing material property of interest.

The ability of the contacting thermoelectric technique detecting small variations in material properties can be limited by the existence of spurious thermoelectric signal related to the inherently imperfect contact between the specimen and the reference electrode [19]. Clearly, conventional thermocouples based on Seebeck effect cannot be used in a noncontacting manner since they require direct electrical and thermal coupling with the specimen to be inspected. However, thermoelectric measurement can be conducted in an entirely noncontacting way by using high-sensitivity magnetic sensors to detect the thermoelectric current caused by inclusions and other types of inhomogeneities when inspected specimen is subjected to direct heating and cooling [20]. Assuming the existence of a defect or imperfection in an otherwise homogeneous material and that a temperature gradient is established throughout the specimen, different points at the boundary between the defect or imperfection and the host material will be at different temperatures, and therefore at different thermoelectric potentials. These potential differences will drive local thermoelectric currents around the affected area, which can be detected in a noncontacting manner by a high sensitive magnetometer. This technique was originally developed for the detection of metallic inclusions in metals, but has shown to be sensitive enough to a series of material imperfections that are currently no detectable or very challenging by any other inspection methods, including cold work, localized texture, residual stress, excess heat, fatigue damage, etc. [21]. 


\section{MATERIAL AND EXPERIMENTAL PROCEDURE}

\subsection{Material and surface conditions}

A Ti6Al4V ELI (extra low interstitial) alloy was used in this study. Rectangular specimens of about $8 \times 25 \mathrm{~mm}^{2}$ and $2 \mathrm{~mm}$ thick were machined and grit blasted with different types of particles under a pressure of $350 \mathrm{kPa}$ for 2 min and with a distance between the nozzle and the target surface of $20 \mathrm{~cm}$. A first set of samples, hereafter BLZrO samples, was blasted using $\mathrm{ZrO}_{2}$ microspheres sized between $125 \mu \mathrm{m}$ and $250 \mu \mathrm{m}$. The second set of samples, hereafter BL-AlO samples, was blasted with $\mathrm{Al}_{2} \mathrm{O}_{3}$ angular particles of $\approx 750 \mu \mathrm{m}$. Blasting was manually performed in such a way that all surfaces become equally modified. For comparative purposes, polished samples, hereafter PL samples, were ground with consecutively finer SiC papers, and finely polished with diamond paste and colloidal silica $(0.5 \mu \mathrm{m})$ to remove the outer surface layer of deformed metal during the sample preparation.

To highlight the effect of residual stresses on the TEP values, a set of blasted samples were annealed at $595{ }^{\circ} \mathrm{C}$ and $710^{\circ} \mathrm{C}$ for $1 \mathrm{~h}$ and $2 \mathrm{~h}$ respectively, then air cooled out of the furnace. Such heat treatments are known to induce a partial and a fully release of the residual stresses, respectively [22].

\subsection{Microstructural characterization}

Roughness of the as-processed specimens was determined with a mechanical profilometer averaging 3 measurements of $4 \mathrm{~cm}$ in length.

Identification of phases present at the outer surface was performed with a conventional X-ray diffractometer furnished with an opened Eulerian cradle. In the setup used, a Xray Co tube is equipped with a Goebel mirror optics to obtain a parallel and 
monochromatic X-ray beam. A current of $30 \mathrm{~mA}$ and a voltage of $40 \mathrm{KV}$ were employed as tube setting.

Microstructural characterization of the surface morphology and cross sections of the treated and untreated specimens was carried out by using a SEM coupled with an energy dispersive X-ray system for chemical analysis. In order to preserve the original blasted surface during sectioning and to avoid artifacts during the measurements performed beneath the surface, selected specimens were electrolytically coated with a fine layer of $\mathrm{Cu}$. The grain structure was revealed by Backscattered Electron Images (BEI) obtained on fresh grinded and polished surfaces operating at low voltages.

\subsection{Microhardness measurements}

Hardness Vickers was measured on transverse polished samples with a microhardness equipment. Loads of $10 \mathrm{~g}$ applied during 15s were used. Hardness profiles were obtained from the near surface to a depth far away from the blasted affected zone. Each value corresponds to average values of al least fourteen indentations.

\subsection{Thermoelectric measurements}

A schematic representation of the contacting thermoelectric technique is given by Figure 1. The sample is pressed between two blocks of pure copper. One of the blocks is at $15^{\circ} \mathrm{C}$, while the other is at $25^{\circ} \mathrm{C}$ to obtain a temperature difference, $\Delta T$. A potential difference, $\Delta V$, is generated at the reference metal contacts. The apparatus does not give the absolute TEP value of the sample ( $\left.\mathrm{S}^{*}\right)$, but a relative TEP (S) in comparison to the TEP of pure copper $\left(S_{0}^{*}\right)$ at $20^{\circ} \mathrm{C}$. The relative TEP value $(S)$ is given by $\mathrm{S}=\mathrm{S}^{*}-\mathrm{S}_{0}{ }^{*}=$ $\Delta \mathrm{V} / \Delta \mathrm{T}$. The measurements are performed very quickly $(<1 \mathrm{~min})$ and precisely $( \pm 0.5 \%)$, with a resolution of about $1 \mathrm{nV} / \mathrm{K}$ [23]. 
On the other hand, in the noncontacting thermoelectric technique each sample is mounted into two pure $\mathrm{Cu}$ supporters which are perforated by a series of holes and equipped with sealed heat exchangers to facilitate efficient heating and cooling. The system is mounted on a nonmagnetic translation table for scanning. In order to get a better heat transfer between the specimen and the $\mathrm{Cu}$ heat exchangers, a layer of silicone heat sink compound was applied. One of the $\mathrm{Cu}$ supporters is at $15^{\circ} \mathrm{C}$, while the other is at $25^{\circ} \mathrm{C}$. The temperature gradient is kept at $\sim 1.2{ }^{\circ} \mathrm{C} / \mathrm{mm}$ in noncontacting TEP measurements, which is more than sufficient to produce detectable magnetic signals in the grit blasted Ti6Al4V alloy samples. A fluxgate magnetometer is used to detect the thermoelectric signals from the grit blasted zone. Since the resulting magnetic field is perpendicular to the heat flux in the specimen (parallel to the surface) and the gradient of the material property (normal to the surface), the magnetometer was polarized in the tangential direction as shown in Figure 2. The lift-off distance between the magnetometer and the sample surface is $\sim 2 \mathrm{~mm}$.

\subsection{Residual stress determination by X-Ray diffraction}

The X-ray stress evaluation methods are based on the use of change on the lattice spacing from those of a stress-free material as a strain gauge. As shown in Figure 3, for each inclination of the sample, defined by $\psi$, the strain $\varepsilon_{\phi \psi}$ in the direction normal to the diffracting planes $\{\mathrm{kkl}\}$, is thus related to the corresponding lattice spacing $d_{\phi \psi}$ as:

$$
\varepsilon_{\phi \psi}=\frac{\mathrm{d}_{\phi \psi}-\mathrm{d}_{0}}{\mathrm{~d}_{0}}
$$

where $d_{0}$ is the stress-free lattice spacing. As for the radiations generally used for stress measurements, $50 \%$ of the radiation is diffracted from a layer of approximately $5 \mu \mathrm{m}$ deep, it is assumed that the stress perpendicular to the surface $\sigma_{3}$ is 0 . Thus, the strain 
$\varepsilon_{\phi \psi}$ in the direction defined by the angles $\phi$ and $\psi$, can be related to the principal components of the stress tensor in the irradiated layer, $\sigma_{1}$ and $\sigma_{2}$, by the equation:

$$
\varepsilon_{\phi \psi}=\left[\frac{1+v}{E}\left(\sigma_{1} \cos ^{2} \phi+\sigma_{2} \sin ^{2} \phi\right) \sin ^{2} \psi\right]-\left[\frac{v}{E}\left(\sigma_{1}+\sigma_{2}\right)\right]
$$

where $E$ is the modulus of elasticity and $v$ the Poisson's ratio. If the angle $\psi$ is taken to be $90^{\circ}$, the strain vector lies in the plane of the surface, and the surface stress component $\sigma_{\phi}$ is:

$$
\sigma_{\phi}=\sigma_{1} \cos ^{2} \phi+\sigma_{2} \sin ^{2} \phi
$$

Substituting equations 1 and 3 into equation 2 yields:

$$
\frac{\mathrm{d}_{\phi \psi}-\mathrm{d}_{0}}{\mathrm{~d}_{0}}=\left[\left(\frac{1+v}{\mathrm{E}}\right)_{(\mathrm{hkl})} \sigma_{\phi} \sin ^{2} \psi\right]-\left[\left(\frac{v}{\mathrm{E}}\right)_{(\mathrm{hkl})}\left(\sigma_{1}+\sigma_{2}\right)\right]
$$

where the elastic constants $(1+v / E)_{(h k l)}$ and $(v / E)_{(h k l)}$ are the values for the crystallographic direction normal to the lattice planes in which the strain is measured (as specified by the Miller indices (hkl)), which can be empirically determined. The lattice spacing for any orientation is then:

$$
\mathrm{d}_{\phi \psi}=\left[\left(\frac{1+v}{\mathrm{E}}\right)_{(\mathrm{hkl})} \sigma_{\phi} \mathrm{d}_{0}\right] \sin ^{2} \psi+\left[\mathrm{d}_{0}-\left(\frac{v}{E}\right)_{(\mathrm{hkl})} \mathrm{d}_{0}\left(\sigma_{1}+\sigma_{2}\right)\right]
$$

This equation is a form of the traditional X-ray residual stress determination. It predicts a linear variation of the lattice spacing $d_{\phi \psi}$ vs. $\sin ^{2} \psi$. The stress $\sigma_{\phi}$ may be obtained from the slop of a least squares line fit of the experimental data measured at several $\psi$.

$$
\sigma_{\phi}=\left(\frac{\mathrm{E}}{1+v}\right)_{(\mathrm{hkl})} \frac{1}{\mathrm{~d}_{0}}\left(\frac{\partial \mathrm{d}_{\phi \psi}}{\partial \sin ^{2} \psi}\right)
$$


This procedure is known as the " $\sin ^{2} \psi$ " technique. Although the unstressed lattice spacing, $d_{0}$, it is generally not available, the value at $\psi=0$ is used for $d_{0}$. This assumption is based on the fact that, for most materials $E »(\sigma 1+\sigma 2)$, and then elastic strain introduces at most $1 \%$ difference between the true $d_{0}$ and $d$ at any $\psi$. Therefore, the error introduced by this assumption in the final stress value is negligible compared to the error introduced by other sources.

\section{RESULTS AND DISCUSSION}

\subsection{Microstructural characterization}

Figure 4 shows backscattered electron images of the surface of polished and blasted specimens before and after heat treatment at the highest temperature $\left(710^{\circ} \mathrm{C} / 2 \mathrm{~h}\right)$. BEI examination of the PL samples, Fig 4a, reveals the typical biphasic structure consisting of a low volume fraction of discontinuous bright particles of irregular size ( $\beta$-phase) into a dark matrix ( $\alpha$-phase). X-Ray diffraction analysis, Table 1 , reveals volume fractions of 15 and $85 \%$ for the $\beta$ - and $\alpha$-phases, respectively. As a consequence of blasting, a severe deformation of the surface occurs that yields a rough surface with a number of irregular intrusions and protrusions of sharp ridges. In addition, particles of heterogeneous size become embedded, as can be seen in Figs. 4c and e (dark contrast). Microanalysis confirmed they are remnants of the jet of particles used for blasting. This feature is particularly important in the case of the BL-AlO samples, Table 1, reaching a volume fraction of up to about $60 \%$.

Annealing treatments aimed to relax residual stresses were performed in air and, as expected, gave rise to oxidation of the specimens. This process is macroscopically manifested by a change in the color of the surface from a grey metallic for the untreated condition to a dark blue for the heat treated ones. X-Ray diffraction analysis, 
Table 1, denotes that the forming oxide scale is mostly rutile. BEI examination of annealed specimens reveals the formation of an adherent and continuous scale. The scale is overgrowth by isolated zones of thicker Ti-rich oxides, Figs. 4b, d, and f, likely remnant of the earliest stages of oxidation where the different composition of the $\alpha$ - and $\beta$-phases promoted a faster kinetics on the last ones. This feature is more evident on the polished surfaces.

Average roughness $(R a)$ of the studied materials is presented in Table 2. $R a$ of polished surface increases with blasting from $0.02 \mu \mathrm{m}$, up to about $0.95 \mu \mathrm{m}$ in the BL-ZrO specimens and $5 \mu \mathrm{m}$ in the BL-AlO specimens. Differences in roughness are mostly related to the angular shape of the alumina grit particles that make them more abrasive. Heat treatments of the PL samples cause an increase in roughness, which is more noticeable when treated at the highest temperature $(0.88 \mu \mathrm{m})$. The increase in roughness is related to the scale formation mechanism, which topography is altered by the thicker oxides grown on the $\beta$-phase zones. Oxide scales also develop on the blasted surfaces, as can be seen in Fig. 4 b, d, and f, but due to the higher roughness of the surface scale spallation is favored at the crests of the surface. The net effect is a spallation/reoxidation process that yields a moderated decrease in roughness.

The presence of the large amount of embedded alumina particles in the BL-AlO samples or rutile in the thermally treated samples, Table 1, made difficult the determination of the residual stresses by X-Ray diffraction. Thus, such analysis was only possible in the case of BL-ZrO samples. Residual stresses were found to be highly compressive (-965.7 $\pm 11.6 \mathrm{MPa})$, in agreement with previous works [7].

Figure 5 shows cross sectional views of the blasted specimens, without heat treatment and after $710^{\circ} \mathrm{C} / 2 \mathrm{~h}$, obtained by BEI to reveal the phases of the alloy and to get, under the appropriate experimental conditions, also contrast of the grains due to differences in 
their crystallographic orientation. Comparative analysis of untreated and treated samples at zones beneath the blasted surface and the sample interior reveals two significant differences in the microstructure. The first one relates to the filamentous morphology of the $\beta$-phase beneath the surface of the untreated blasted samples, Figure $5 \mathrm{a}$ and $\mathrm{c}$, which denotes a severely deformed region, about 2-4 $\mu \mathrm{m}$ thick. This deformation is more evident in the BL-AlO specimen, Figure $5 c$, than in the BL-ZrO one, Figure 5a. This morphology of the $\beta$-phase contrasts with the rather homogeneous distribution in the bulk, where it forms a cellular-type structure that encloses quite equiaxed $\alpha$-grains, as shown in Fig. 4a. The severe deformation beneath the surface is also manifested in the untreated blasted specimens at higher magnifications (not shown) by the presence at the $\alpha$-phase of an ultrafine/deformed grained structure.

Annealing of the blasted material gives rise to a thermal oxidation characterized by the formation of thin oxide scales, being thickness slightly higher for the highest temperature $(<2 \mu \mathrm{m})$. Sub-surface microstructure is also modified, as illustrated in Figures $5 \mathrm{~b}$ and $\mathrm{d}$ for samples annealed at $710{ }^{\circ} \mathrm{C}$. This effect is especially evident in the BL-AlO specimen, Figure $5 \mathrm{~d}$, where $\beta$-phase become globular and $\alpha$ grains become larger and equiaxial, without any sign of plastic deformation, which is indicative of a recovery/recrystallization process. Variations in the volume fraction of the $\beta$-phase are difficult to quantify by X-Ray diffraction, due to the formation of the outer oxide scale, but a moderated increase is envisaged from the comparative analysis of BEI images, which would be consistent with a progressive approach to the equilibrium conditions. The large amount of dislocations in the blasted affected zone contributes to enlarge the diffusion rates, thus this effect is less evident in the interior of the sample. The evolution of the $\beta$-phase at the blasted affected zones would be accompanied by changes in the solute concentration. Attempts to quantify compositional changes at the blasted affected 
zones was challenged by the scattering of results, but it could be pointed out a moderated average increase in the $\mathrm{V}$ content of the $\alpha$-phase located at the blasted affected zones of the annealed specimens, which is counterbalanced by a decrease in the $\mathrm{V}$ content of the $\beta$-phase. The intermediate heat treatment of $595{ }^{\circ} \mathrm{C}$ gave rise to intermediate microstructures between those of the untreated and $710{ }^{\circ} \mathrm{C}$ treated specimens.

Hardness measurements were determined on the cross sections at zones within the blasted affected zone (10 and $30 \mu \mathrm{m})$ and well far away $(1000 \mu \mathrm{m})$. Load was very small (10 g) to obtain indentations of small size and then approach to the blasted surface as much as possible. Since size of the imprints is similar to that of the $\beta$-phase, scattering of results was rather high. Overall, the blasting treatment does not influence the Ti6Al4V alloy hardness, irrespectively the particles used for blasting, due to his very low hardening rate exponent [7]. For illustrative purposes, Fig. 6 shows the hardness profile for the untreated and $710{ }^{\circ} \mathrm{C}$ treated BL-AlO specimens. Taking into consideration the error bars, it cannot be ascertained that a hardening beneath the grit blasted surface occurred, Fig. 4a. Furthermore, the heat treatment did not affect the hardness of the alloy.

\subsection{Thermoelectric power measurements}

Ti6Al4V samples were tested using the contacting and noncontacting thermoelectric techniques. The relative contacting TEP value of the investigated samples is shown in Fig. 7. It is important to remark that untreated and thermally treated polished samples exhibit similar values, which suggests that an annealing treatment without a grit blasting practice does not contribute to the contacting TEP measurement. The moderated smaller values found for the thermally treated specimens could be related with the development of the outer oxide layer, which is thicker for the specimen treated at $710{ }^{\circ} \mathrm{C}$, and the 
annihilation of dislocations introduced during polishing [24]. Therefore, differences found with regards to the blasted specimens correspond to microstructural changes in the blasted affected zones that in the present specimens, with two opposite blasted surfaces, represent about $10 \%$ of the specimen thickness.

The contacting TEP value for the blasted surfaces, Fig. 7, is higher than that for the unblasted condition. Annealing treatments causes a gradual decrease of the relative TEP values. It is worth noting that differences in this trend between BL-ZrO and BL-AlO samples are insignificant, which discard any relevant effect of the differences in roughness and in the amount of embedded ceramic particles in the outer part. Relevant for this investigation is that after annealing at $710{ }^{\circ} \mathrm{C}$ the TEP values are still much higher than that corresponding to the polished condition. The evolution of the TEP values can be correlated with the moderate grain size increase and a growth of the $\beta$ phase at the blasted affected zones, Fig. 5, which implies local changes in the V content [23]. The decrease of the TEP value with increasing annealing temperature was not observed for the grit blasted 316 LVM steel, [11] but in this case phase evolution was not found. Contribution of the release of residual stress and decrease of the large density of dislocations introduced by the severe plastic deformation process [26] must be very small since the monitored signal after full stress relaxation $\left(710^{\circ} \mathrm{C} / 2 \mathrm{~h}\right)$ is still much higher than that corresponding the unblasted specimens, highlighting the contribution of the remnant effects in the blasted affected zone.

Analysis of the non-contacting TEP values, Fig 8, reveals that the flux density increased significantly from $\sim 1.5 \mathrm{nT}$ (polished) to $~ 6.5$ and $11 \mathrm{nT}$ (blasted) for the BL-ZrO and BL-AlO samples, respectively. Then, the flux density decreased gradually after the first stress relaxation treatment $\left(595{ }^{\circ} \mathrm{C} / 1 \mathrm{~h}\right)$. Finally, on the second stress relaxation treatment $\left(710^{\circ} \mathrm{C} / 2 \mathrm{~h}\right)$, the flux density was reduced to a value similar to that of the 
polished and treated condition. This feature indicates that this technique is not sensible to the remnant microstructural blasted induced effects described above. Therefore, the variation in the related flux density exclusively correlates to the relaxation of the compressive residual stresses [11,21]. Decrease in the flux density for the polished samples denotes the relaxation of the compressive residual stresses introduced during polishing.

It is worth noticing that the magnetic flux density does not completely vanish after complete stress release. This intrinsic background signature is caused by the crystallographic anisotropy [21,27]. Texture-induced anisotropy can also lead to significant thermoelectric signals between regions of different orientation [28]. Generally, the anisotropy is partly due to partial alignment of the crystallographic orientations of the neighboring grains and partly to morphological features such as preferred orientation of elongated grain boundaries, dislocations, slip bands, etc. It should be mentioned that, in contrast to mechanical properties, thermoelectric properties of cubic materials aluminum, copper, nickel, steel, etc. do not exhibit crystallographic anisotropy. The few structural metals of great practical importance that preferentially crystallize in noncubic hexagonal symmetry, therefore, do exhibit thermoelectric anisotropy, are titanium and its alloys. Another important effect that might contribute to the thermoelectric material signature is the substantial stress dependence of the thermoelectric power [29] that could result in significant point-to-point variations as well as orientation dependence when residual or externally induced stresses are present in the material. 


\section{CONCLUSIONS}

In the current research, TEP measurements were applied as a non-destructive assessment technique to detect subtle material variations produced by the manufacturing process of grit blasting in a medical Ti-6Al-4V alloy. It has been shown that contacting TEP measurements are strongly influenced by the microstructural changes induced by blasting. Upon stress relief annealing, TEP values gradually decay after the first and second treatments as a consequence of recovery/recrystallisation processes. However, after the second annealing, TEP values of blasted specimens do not reach the un-blasted one. This indicates that the contacting technique is sensitive to other minor changes, such as increase of $\beta$-phase volume fraction that implies local changes in solute.

Non-contacting TEP values of blasted specimens are much higher than those of unblasted one. During the annealing processes, TEP values of blasted specimens gradually decay. After the total stress relief annealing, TEP values reach the un-blasted one. This fact indicates that the non-contacting technique applied to blasted surfaces is able to detect the presence of residual stresses.

\section{ACKNOWLEDGMENTS}

This work was performed at UMSNH (Mexico) and CENIM-CSIC (Spain) with a partial funding from CONACYT (Mexico) under project CB-80883 and MAT200914695-C04. The author H. Carreón wishes to thank CONACYT (Mexico) for the financial support during the sabbatical in CENIM-CSIC and S. Barriuso for the JAEPre082-3 of CSIC-UE. 


\section{REFERENCES}

1.- T. Jinno, V.M. Goldberg, D. Davy, S. Stevenson, J. Biomed. Mater. Res A 42:1 (1998) 20.

2.- A. Wennerberg, T. Albrektsson, B. Andersson, Int. J. Oral Maxillofac. Implants 11 (1996) 38.

3.- I. Altenberger, B. Scholtes, U. Martin, H. Oettel, Mater. Sci. Eng. A. 264 (1999) 1.

4.- M. Multigner, E. Frutos, J. Chao, J.L. González-Carrasco, Surf. Coat. Technol., 203 (2009) 2036.

5.- J.C. Galván, L. Saldaña, M. Multigner, M. Larrea, A. Calzado-Martín, C. Serra, N. Vilaboa, J.L. González-Carrasco, J. Mater. Sci. Mater. Med. 23 (2012) 657.

6.- M.C. García-Alonso, M.L. Escudero, J.L. González-Carrasco, J. Chao, Biomaterials $21(2000) 79$.

7.- M. Multigner, P. Fernández-Castrillo, S. Ferreira-Barragán, G. González-Doncel, J.L. González-Carrasco, Revista de Metalurgia. 45 (2009) 52.

8.- M. Multigner, S. Ferreira, E. Frutos, M. Jaafar, J. Ibáñez, P. Marín, T. Pérez-Prado, G. González-Doncel, A. Asenjo, J.L. González-Carrasco, Surf. Coat. Technol. 205 (2010) 1830.

9.- E. Frutos, M. Multigner, J.L. González-Carrasco, Acta Mater. 58 (2010) 4191.

10.- M. Multigner, E. Frutos, J.L. González-Carrasco, J.A. Jiménez, P. Marín, J. Ibáñez, Mater. Sci. Eng. C 29 (2009) 1357.

11.- H. Carreon, S. Barriuso, G. Barrera, J.L. González-Carrasco, F.G. Caballero, Surf. Coat. Technol. 206 (2012) 2941.

12.- Y. Kawaguchi, S. Yamanaka, J. Alloys Compd. 336 (2002) 301.

13.- S. Carabajar, J. Merlin, V. Massardier, S. Chabanet, Mater. Sci. Eng. A 281 (2000) 132.

14.- M. Bächle, R.J. Kohal, 2004. Clin. Oral Implants Res.15:6 (2004) 683.

15.- L. Saldaña, V. Barranco, J.L. González-Carrasco, M. Rodríguez, L. Munuera, N. Vilaboa, J. Biomed. Mater. Res. Part A 81A (2007) 334. 
16.- V. Barranco, M.L. Escudero, M.C. García-Alonso, Acta Biomater. 7:6 (2001) 2716.

17- E.B. Henry, C.M. Stuart, W. Tomasulo, Nondestructive testing handbook. ASNT 9, (1195) 363.

18.- C.M. Stuart, Inter. Adv. Nondestr. Test. 9 (1983) 177.

19.- J. Hu, P.B. Nagy, Appl. Phys. Lett. 73 (1998) 467.

20. - K. Maslov, V.K. Kinra, Mater. Eval. 59 (2001) 1081.

21.- H. Carreon, NDT\&E Int. 39 (2006) 433.

22.- E. Boyer, G. Welsch, G., E.W. Collins, Materials Properties Handbook, Titanium Alloys, ASM International (1994) 606.

23.- J.A. Ney, Metall. Mater. Trans. A 29 (1998) 2669.

24.- J.P. Ferrer, T. De Cock, C. Capdevila, F.G. Caballero, C. García de Andrés, Acta Materialia 55 (2007) 2075.

25.- F.G. Caballero, C. Capdevila, L.F. Alvarez, C. Garcia de Andres, Scripta Materialia 50 (2004) 1061.

26.- N.I. Kourov, V.G. Pushin, A.V. Korolev, V.A. Kazantsev, E.B. Marchenkova, A.N. Uksusnikov, The physics of metals and metallography. 103 (2007) 270.

27.- A.H. Nayfeh, H. Carreon, P.B. Nagy, J. Appl. Phys. 91 (2002) 225.

28.- V.A. Rowe, P.A. Schroeder, J. Phys. Chem. Solids 31 (1970) 1.

29.- F.P. Bundy, J.Apply. Phys. 32 (1961) 483. 


\section{Figure Captions}

Table 1 Percentage of phases determined by X-Ray diffraction at the surface of polished (PL) and blasted (BL) samples with and without thermal treatment $\left(710^{\circ} \mathrm{C} / 2 \mathrm{~h}\right)$.

Table 2 Roughness ( $R a)$ of polished and blasted specimens with and without relaxation thermal treatments.

Figure 1 Schematic diagram of the contacting thermoelectric technique as used for the characterization of grit blasted samples.

Figure 2 Schematic diagram of the noncontacting thermoelectric technique as used for the characterization of the grit blasted samples.

Figure 3 Change in lattice spacing with tilt $\psi$ for a uniaxial stress $\sigma_{\phi}$ parallel to one edge.

Figure 4 Backscattered electron images obtained on the surfaces of: a) PL, b) PL (710 $\left.{ }^{\circ} \mathrm{C} / 2 \mathrm{~h}\right)$, c) BL-ZrO, d) BL-ZrO (710 $\left.{ }^{\circ} \mathrm{C} / 2 \mathrm{~h}\right)$, e) BL-AlO, f) BL-AlO $\left(710^{\circ} \mathrm{C} / 2 \mathrm{~h}\right)$.

Figure 5 Backscattered electron images obtained on cross sections close to the blasted surfaces of: a) $\mathrm{BL}-\mathrm{ZrO}, \mathrm{b}) \mathrm{BL}-\mathrm{ZrO}\left(710^{\circ} \mathrm{C} / 2 \mathrm{~h}\right)$, c) $\left.\mathrm{BL}-\mathrm{AlO}, \mathrm{d}\right)$ BL-AlO (710 $\left.{ }^{\circ} \mathrm{C} / 2 \mathrm{~h}\right)$. OX: oxide scale, Cu: electrodeposited copper layer.

Figure 6 Vickers hardness (HV) of untreated and $710^{\circ} \mathrm{C} / 2 \mathrm{~h}$ treated BL-AlO Ti6Al4V alloy as a function of distance to the eroded surface.

Figure 7 Relative contacting TEP measurements of unblasted and blasted Ti6Al4V samples.

Figure 8 Relative noncontacting TEP measurements of unblasted and blasted Ti6Al4V samples. 
Table 1. Percentage of phases determined by X-Ray diffraction at the surface of polished (PL) and blasted (BL) samples with and without thermal treatment (710 $\left.{ }^{\circ} \mathrm{C} / 2 \mathrm{~h}\right) .(-)$ not applicable; $(*)$ not detected.

\begin{tabular}{|l|c|c|c|c|c|c|}
\hline \multirow{2}{*}{ Phases } & \multicolumn{2}{|c|}{$\mathrm{PL}$} & \multicolumn{2}{c|}{ BL-ZrO } & \multicolumn{2}{c|}{ BL-AlO } \\
\cline { 2 - 7 } & Un treated & $710^{\circ} \mathrm{C} / 2 \mathrm{~h}$ & Un treated & $710^{\circ} \mathrm{C} / 2 \mathrm{~h}$ & Un treated & $710^{\circ} \mathrm{C} / 2 \mathrm{~h}$ \\
\hline$\alpha-\mathrm{Ti}$ & 84.59 & 17.06 & 72.9 & 38.0 & 32.5 & 10.71 \\
\hline$\beta-\mathrm{Ti}$ & 15.41 & $*$ & 15.5 & 2.84 & 6.5 & $*$ \\
\hline Alumina & - & - & - & - & 60.9 & 42.56 \\
\hline Zirconia & - & - & 11.6 & 3.49 & - & - \\
\hline Rutile & - & 82.94 & - & 55.7 & - & 46.73 \\
\hline
\end{tabular}

Table 2. Roughness $(R a)$ of polished and blasted specimens with and without relaxation thermal treatments

\begin{tabular}{|l|l|l|l|}
\hline \multirow{2}{*}{$R a(\mu \mathrm{m})$} & \multirow{2}{*}{ Untreated } & \multicolumn{2}{|c|}{ Thermally treated } \\
\cline { 3 - 4 } & & $595^{\circ} \mathrm{C} / 1 \mathrm{~h}$ & $710^{\circ} \mathrm{C} / 2 \mathrm{~h}$ \\
\hline $\mathrm{PL}$ & $0.02 \pm 0.001$ & $0.13 \pm 0.01$ & $0.88 \pm 0.06$ \\
\hline BL-ZrO & $0.95 \pm 0.04$ & $0.94 \pm 0.08$ & $0.32 \pm 0.02$ \\
\hline BL-AlO & $5.13 \pm 0.45$ & $4.03 \pm 0.38$ & $3.97 \pm 0.72$ \\
\hline
\end{tabular}




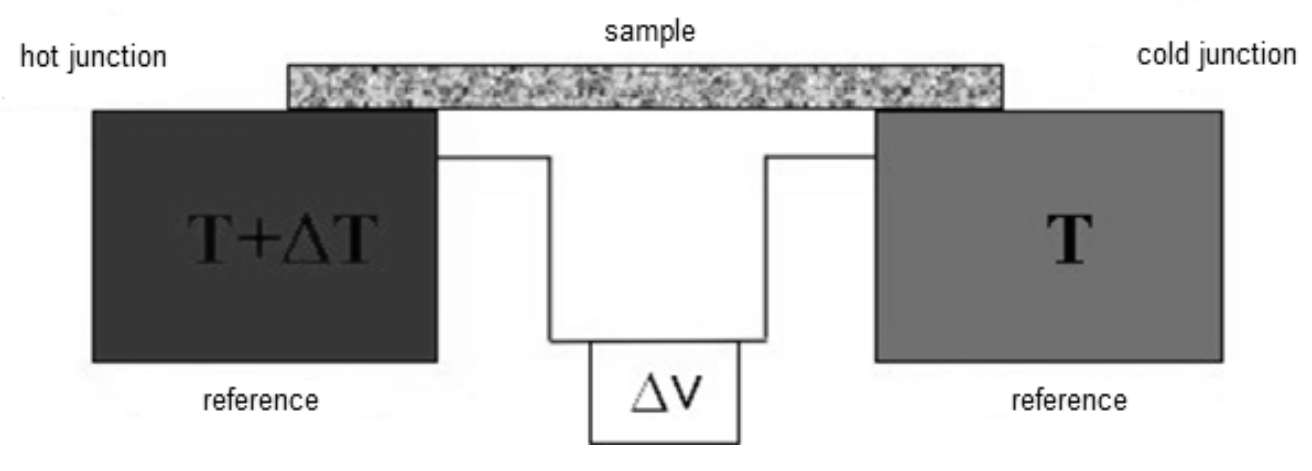

Figure 1. Schematic diagram of the contacting thermoelectric technique as used for the characterization of grit-blasted samples. 


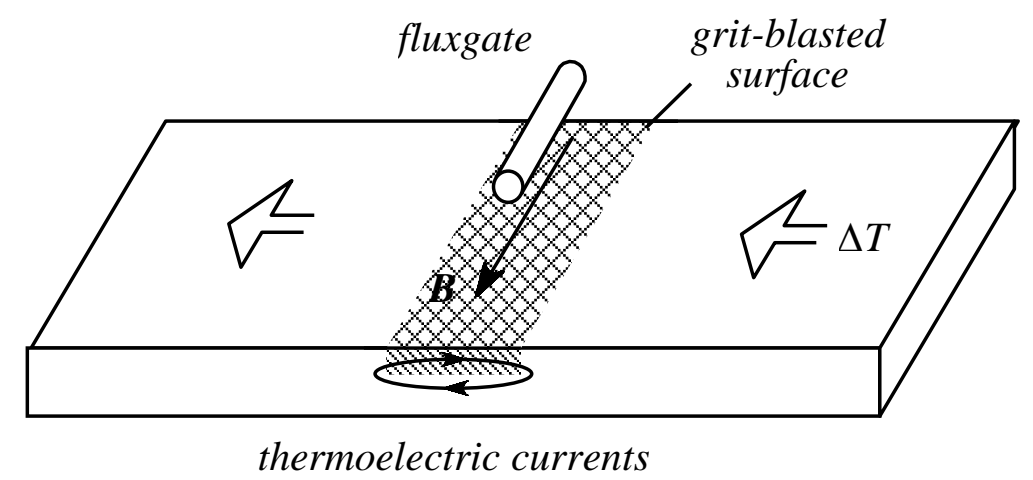

Figure 2. Schematic diagram of the noncontacting thermoelectric technique as used for the characterization of the grit-blasted samples 


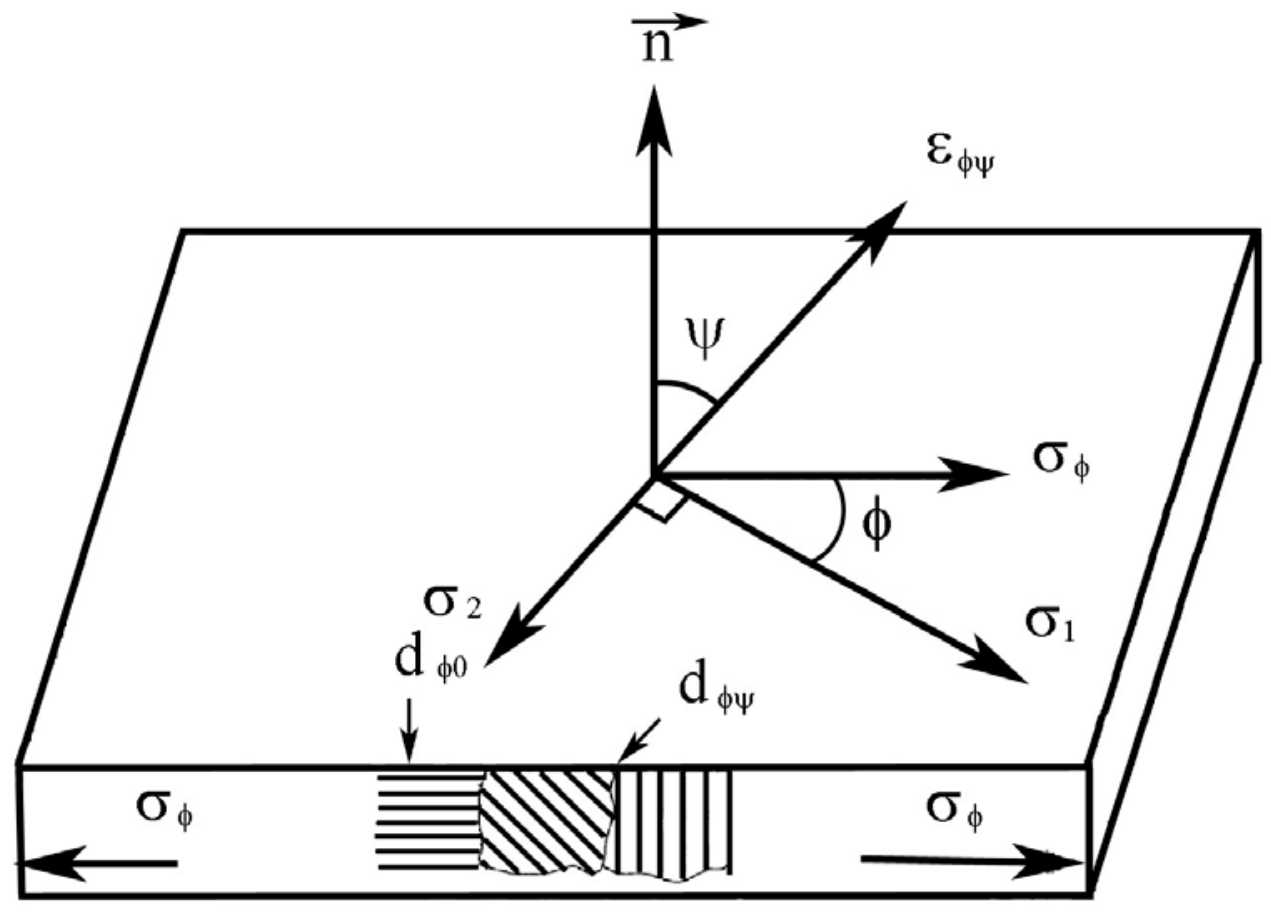

Figure 3. Change in lattice spacing with tilt $\psi$ for a uniaxial stress $\sigma_{\phi}$ parallel to one edge. 

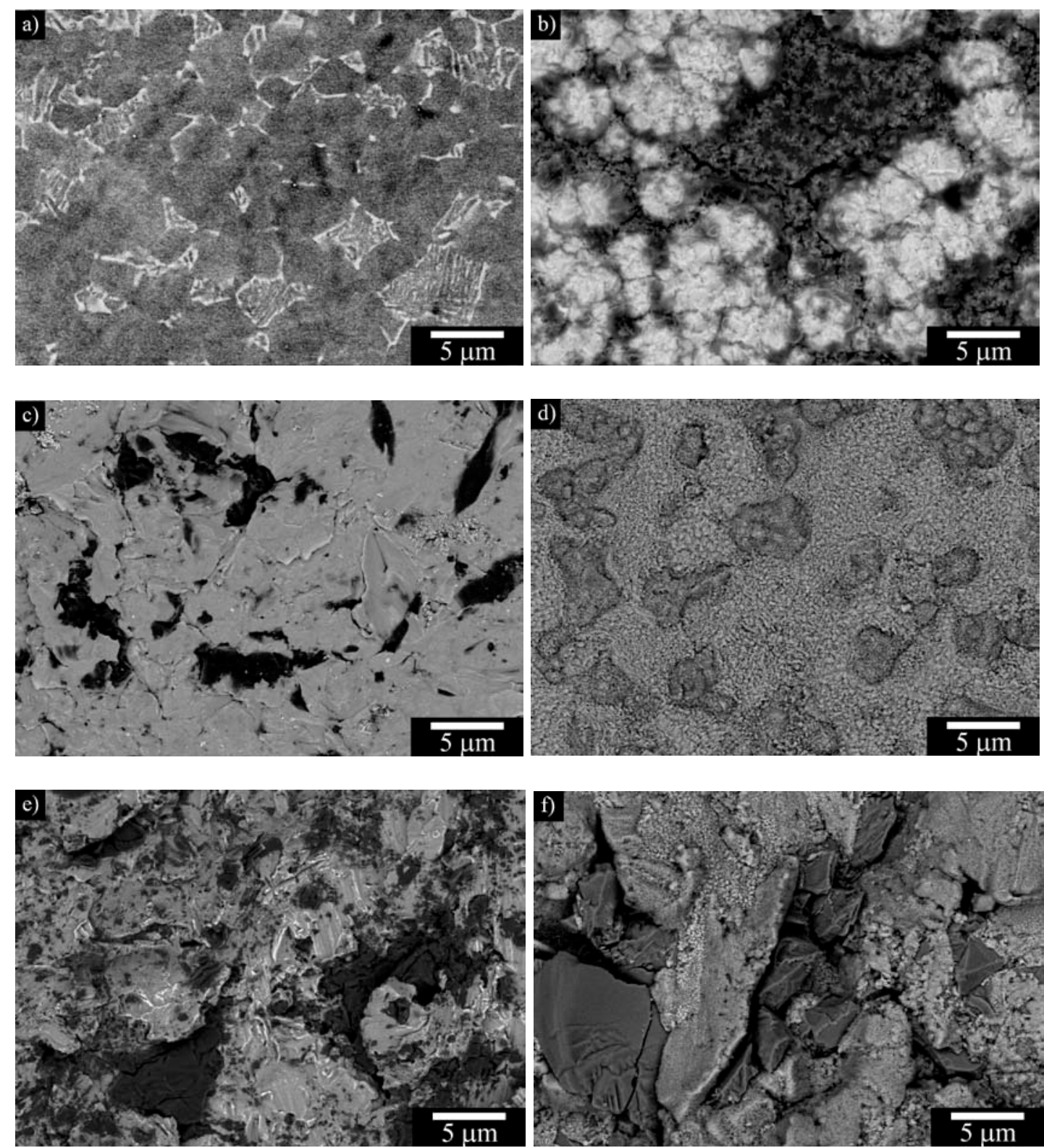

Figure 4 Backscattered electron imagen obtained on the surfaces of : a) PL, b) PL (710 $\left.{ }^{\circ} \mathrm{C} / 2 \mathrm{~h}\right)$, c) BL-ZrO, d) BL-ZrO (710 $\left.{ }^{\circ} \mathrm{C} / 2 \mathrm{~h}\right)$, e) BL-AlO, f) BL-AlO, (710 $\left.{ }^{\circ} \mathrm{C} / 2 \mathrm{~h}\right)$. 

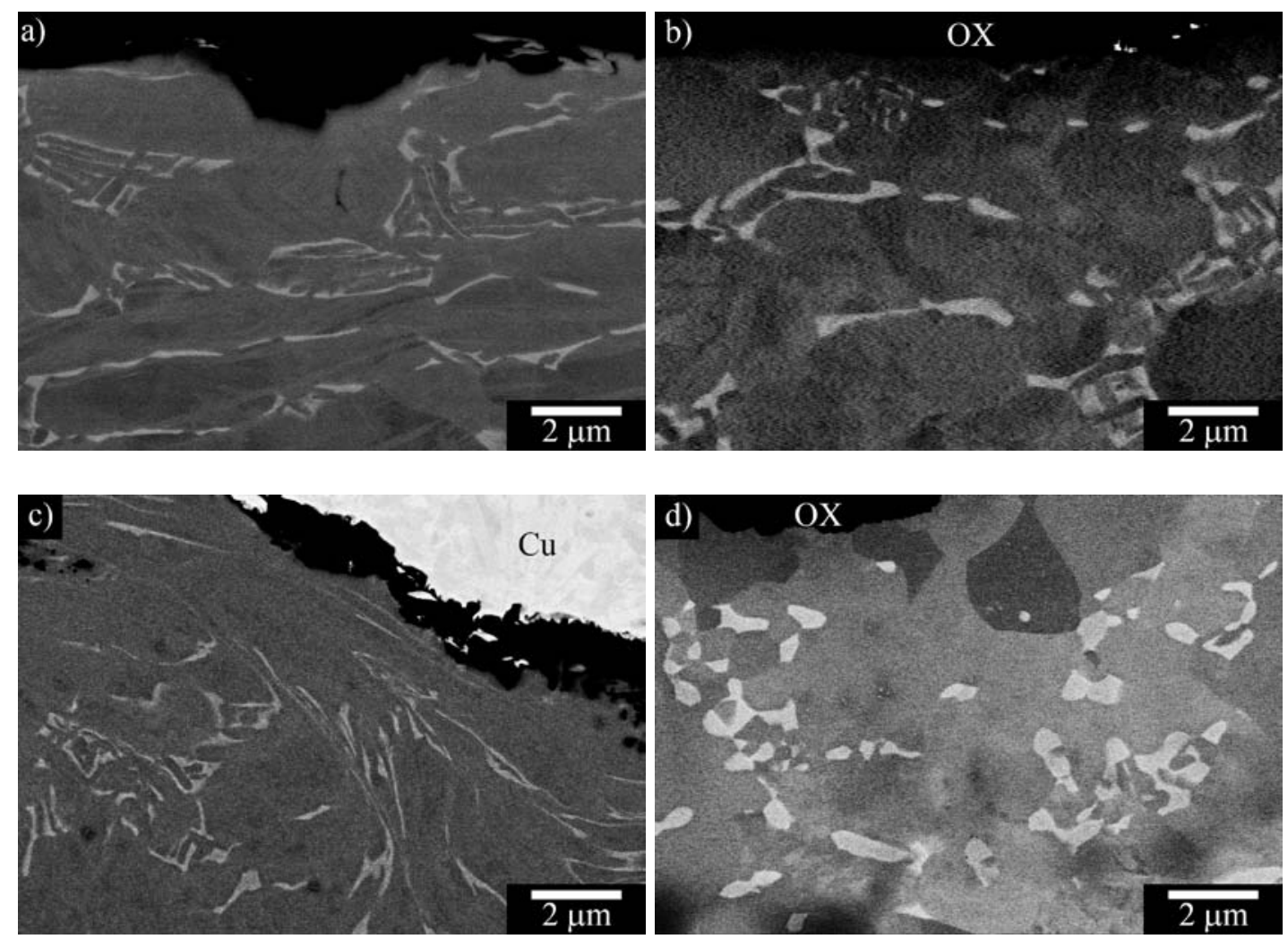

Figure 5 Backscattered electron images obtained on cross sections close to the blasted surfaces of : a) BL-ZrO, b) BL-ZrO (710 $\left.{ }^{\circ} \mathrm{C} / 2 \mathrm{~h}\right)$, c) BL-AlO, d) BL-AlO (710 $\left.{ }^{\circ} \mathrm{C} / 2 \mathrm{~h}\right)$. OX : oxide scale, $\mathrm{Cu}$ : electrodeposited copper layer. 


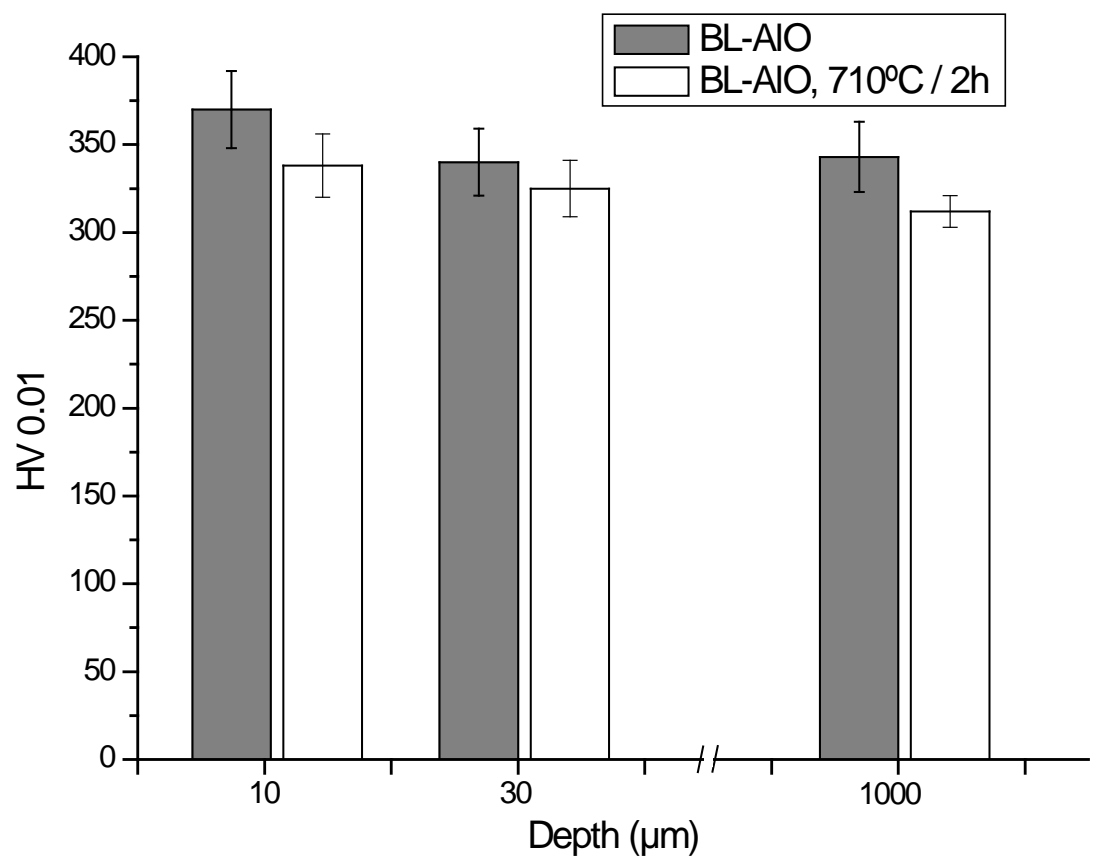

Figure 6 .Vickers hardness (HV) of untreated and $710^{\circ} \mathrm{C} / 2 \mathrm{~h}$ treated BL-AlO Ti6Al4V alloy as a function of distance to the eroded surface. 


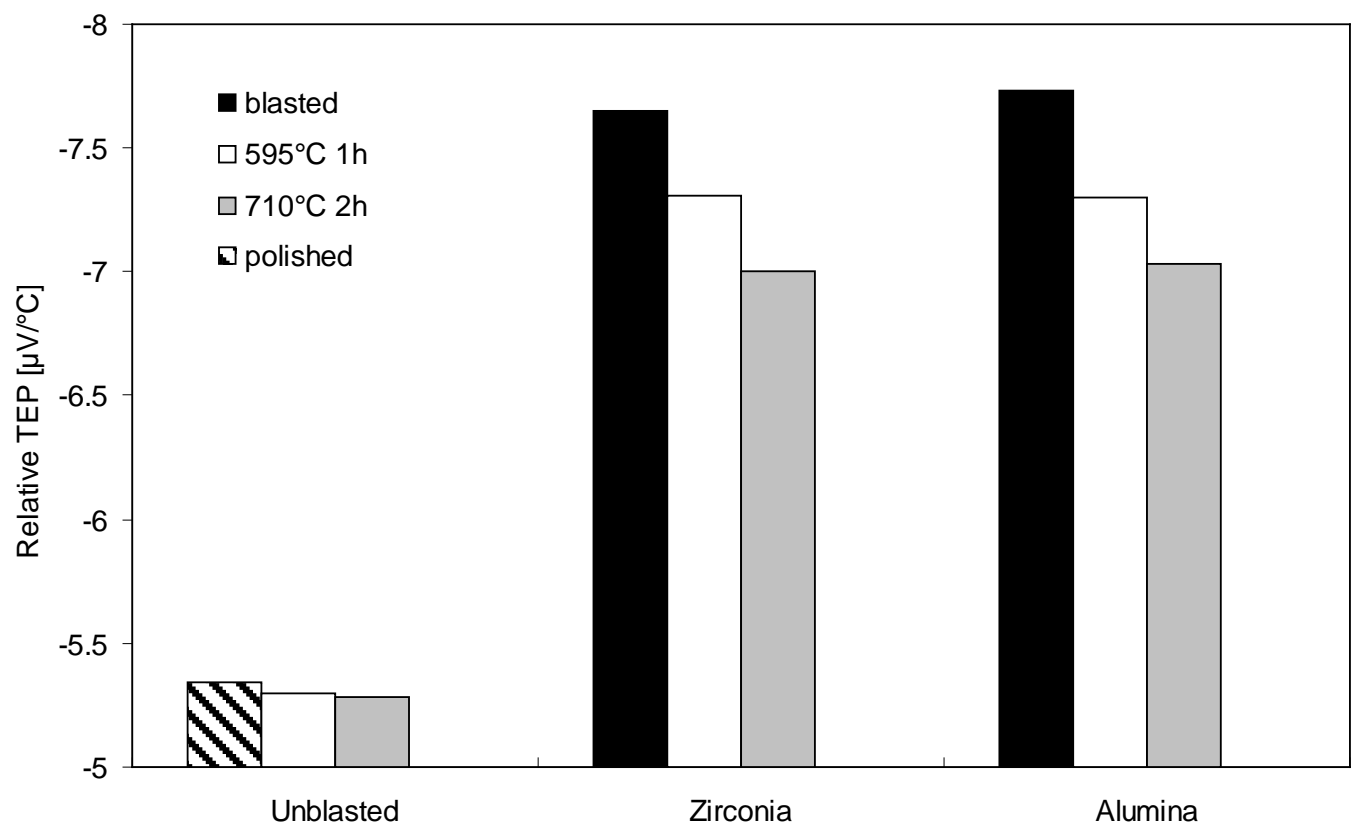

Figure 7. Relative contacting TEP measurements of unblasted and blasted Ti-6Al-4V samples. 


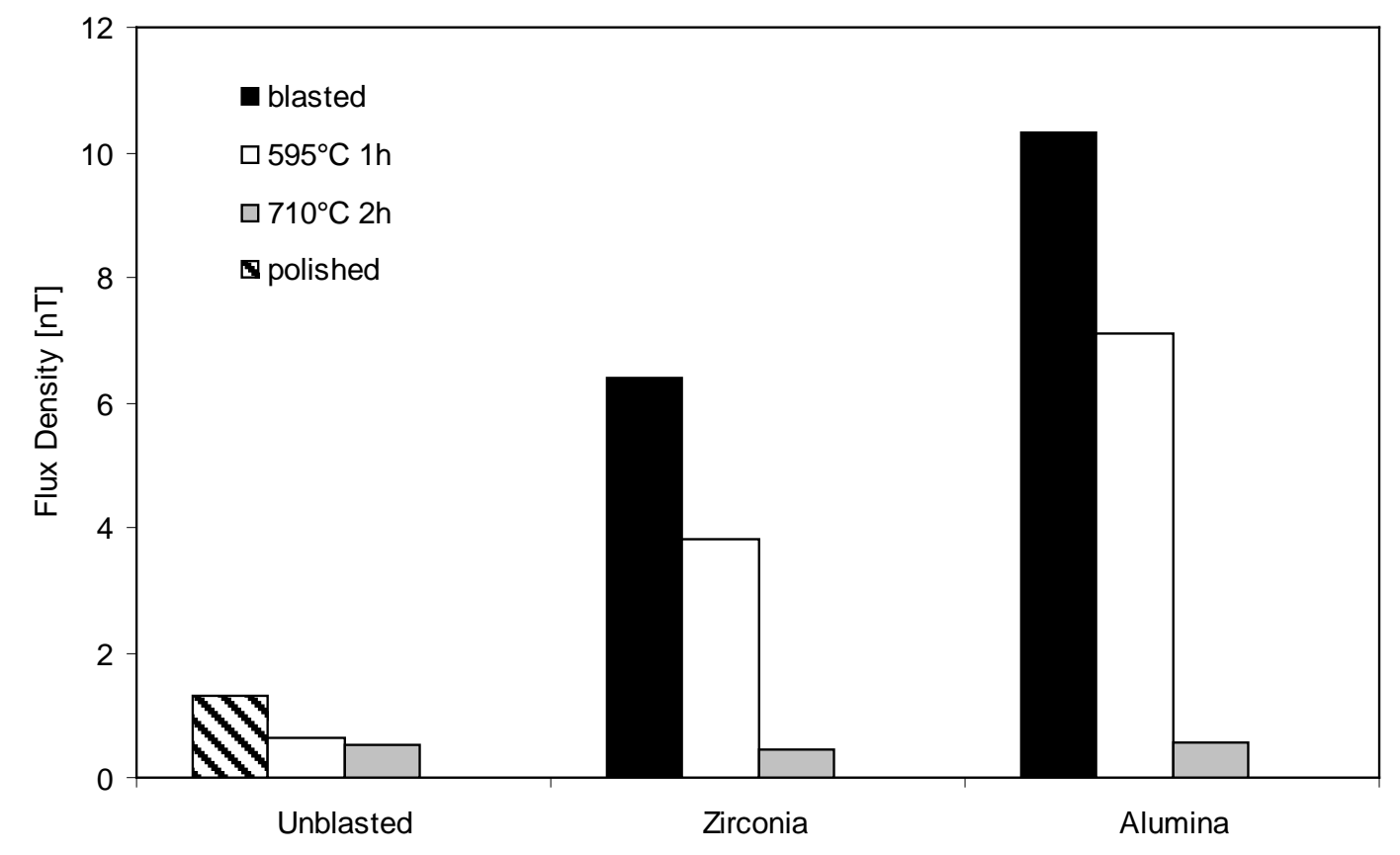

Figure 8. Relative noncontacting TEP measurements of unblasted and blasted Ti-6Al$4 \mathrm{~V}$ samples. 